\title{
DESIGN OF STEEL PORTAL FRAME BUILDINGS FOR FIRE SAFETY
}

\author{
P.J. Moss ${ }^{1 \dagger}$, R.P. Dhakal ${ }^{2}$, M.W. Bong ${ }^{3}$ and A.H. Buchanan ${ }^{4}$
}

\begin{abstract}
This paper describes a study into the fire behaviour of steel portal frame buildings at elevated temperatures using the finite element programme SAFIR. The finite element analysis carried out in this report is three dimensional and covers different support conditions at the column bases, the presence of axial restraints provided by the end walls, different fire severities within the building, different levels of out-of-plane restraint to the columns and the effect of concrete encasement to the columns. From a large number of analyses, it is shown that the bases of the steel portal frames at the foundations must be designed and constructed with some level of fixity to ensure that the structure will deform in an acceptable way during fire, with no outwards collapse of the walls. The analyses also show that to avoid sidesway (i.e. collapse outwards) it is not necessary for steel portal frame columns to be fire-protected unless the designer wishes to ensure that the columns and the wall panels remain standing, during and after the fire.
\end{abstract}

Keywords: fire safety, steel portal frames, structural fire behaviour, finite element analysis

\section{INTRODUCTION}

Steel portal frame buildings with concrete tilt-up panels are a very common form of industrial building in New Zealand and Australia. The parallel steel portal frames are the major framing elements which support the roof of long-run corrugated steel sheeting attached to cold-rolled steel purlins spanning between the portal frames. Large clear spans of up to 40 metres or more can be achieved. Concrete tilt-up wall panels are commonly used as boundary walls as they allow fast erection and on-site fabrication. It is common to encase all or part of the steel portal frame column leg with concrete, or to use a reinforced concrete column for the lower part of the portal frame leg as shown in Figure 1 [1].

In the past, concrete boundary wall panels in New Zealand were required to remain standing after a fire, but it is now considered acceptable for the panels to collapse inwards after a

\footnotetext{
${ }^{1}$ Associate Professor, Department of Civil Engineering, University of Canterbury, Private Bag 4800, Christchurch 8120, New Zealand,

Phone: +6433642245

Fax: $\quad+6433642758$

email: peter.moss@canterbury.ac.nz

${ }^{\dagger}$ Corresponding author

2 Senior Lecturer, Department of Civil Engineering, University of Canterbury, Private Bag 4800, Christchurch 8120, New Zealand,

email: rajesh.dhakal@canterbury.ac.nz

3 Engineer, Arup Fire, Brisbane, Queensland, Australia, email: kelvin.bong@arup.com.au

${ }^{4}$ Professor, Department of Civil Engineering, University of Canterbury, Private Bag 4800, Christchurch 8120, New Zealand, email: andy.buchanan@canterbury.ac.nz
} 
period of time, provided that they remain connected to each other. The Building Code requirements are intended to prevent spread of fire to adjacent properties, hence inwards collapse of boundary walls can actually increase the fire separation distance to the boundary and reduce the likelihood of horizontal fire spread by radiation. The inwards collapse may also extinguish the fire directly beneath the collapsed walls. However there remains concern that under fire conditions, the concrete panels may collapse outwards, creating a danger to fire-fighters and to adjacent property. This project investigates the fire behaviour of portal frame industrial buildings and explores design measures to achieve the goal of avoiding the outward collapse of the wall panels in fire.

In this study, the deformation mode is considered to be either acceptable or unacceptable. Typical acceptable or unacceptable deformation modes of such buildings under fire are shown in Figure 2 [2]. For the frames collapsing inside the building (inwards collapse), it can be seen that the resulting deformation will not endanger adjacent property or persons located outside the building provided that the boundary walls are tied together and fall inwards as a complete unit. In contrast, frames that sway sideways may collapse outwards due to P-delta effects and may lead to adjacent property being damaged or persons outside the building being endangered. Figure 3 shows a situation where except for one wall panel that has collapsed outwards, the wall panels have remained vertical while the portal frames have collapsed inwards.

Although new fire design guidelines [3] in New Zealand have aimed to ensure that the walls either remain upright or collapse inside the building, these design recommendations have not been verified by experiment or by actual fires. The analytical investigation described in this paper is intended to check if the existing regulations and guidelines are indeed sufficient to ensure that the wall panels do not collapse outwards, or if some additional precautions need to be taken during design and/or construction. This study presents an analytical investigation of the fire performance of typical steel portal frame buildings in New Zealand with particular reference to the portal frame base conditions and the need, or otherwise, for concrete encasement of the columns, and establishes amended fire design guidelines for such buildings.

\section{STRUCTURAL DETAILS/DESIGN}

\subsection{Target structure}

The structure studied is a typical industrial building in Christchurch, New Zealand, consisting of five parallel steel portal frames composed of 410UB54 sections as the major framing elements as shown in Figure 4. The roof structure consists of cold-formed DHS250/15 purlins with DB89/10 brace channels between all the purlins at mid-span to prevent buckling. The building was designed according to the New Zealand Loadings Standard NZS 4203:1992 [4] and Steel Standard NZS 3404:1997 [5]. The building is 40 metres long by 30 metres wide and the roof is inclined at $7.9^{\circ}$. The steel frames have a span of 30 metres and are spaced at 7.2 metres. The columns are 6 metres high and the distance from ground level to the apex of the frame is 8 metres. The columns are encased in concrete up to a height of $4 \mathrm{~m}$ and fixed at the base to cantilever foundations. The purlins are spaced equally at 1.5 metres and span between the steel frames. The $125 \mathrm{~mm}$ thick reinforced concrete precast wall panels (not shown in Figure 4) are connected to the columns at two locations (middle and the top) through steel connectors. There is no connection between the wall panels and the floor. 


\subsection{Modelling of the structure}

The building was modelled by using frame elements for the columns, rafters and the purlins. The diaphragm action of the corrugated steel roof sheeting was ignored in the analysis but the self-weight was included. While this diaphragm action helps provide structural rigidity for the roof under ambient conditions, this is not likely to be the case as the steel becomes hot and looses strength and stiffness. In the actual building, the columns were attached to the wall panels at the top and mid-height, and the end of the purlins were supported on the end walls. The wall panels were not explicitly included in the analytical model but were represented by providing fixed restraints to the columns at the two points where they were connected to the wall panels in the actual structure, and also at the ends of the purlins. Explicitly modelling the wall panels will enable the analysis to directly capture the P-delta effect, but at the same time the analysis will require a great deal of computational capacity as the number of elements will be very large. The restraints at the wall-frame connection points (i.e. mid-height and the top) are required under ambient conditions to reduce the effective lengths of the columns to prevent buckling about the weak axis and to prevent out-of-plane displacement at the top and mid-height of the columns.

Because different levels of base fixity are used for typical industrial buildings in New Zealand, frames with fixed and pinned bases were analysed as these provide the upper and lower bound of the base-fixity of the structure. However, fully pinned or fully fixed frame bases are never achieved in reality and some degree of fixity or flexibility will always be provided from the bolted connections at the supports. A portal frame structure with partial base fixity at the supports was also analysed [6]. The loads applied to the analytical model are the self-weight of the steel members and the steel roofing. With this load, the load ratios (defined as the ratio of the expected loads on the structure during a fire to the loads that would cause collapse at normal ambient temperatures), calculated for the steel portal frames with ideally pinned and fixed support conditions are 0.21 and 0.18 , respectively (i.e. lower load ratio signifies better fire resistance).

Two extreme cases were investigated in this project for the purlin support conditions to the end walls (Figure 5), and they are referred to here as either with or without purlin axial restraint. The most important difference between these two support conditions is the translational fixity in the longitudinal direction of the purlins (i.e. purlin axial restraint) at the locations of the end walls. The axial restraints in the steel purlins can be achieved provided the bolted end connections have sufficient axial load capacity. In a real building, the actual level of purlin axial restraint provided by the end concrete walls will certainly lie somewhere between the two extremes modelled in this project, i.e. unrestrained and fully restrained..

In practice, it is common in New Zealand to protect all or part of the steel portal frame column legs with concrete encasement. However, concrete encasement may fall off when exposed to very high temperatures or when the steel portal frame deforms excessively. In addition, when the concrete panels are trying to bow away from the supporting structures due to high temperatures on one side (i.e. thermal bowing effects), the forces developed in the connections between the steel frames and the attached concrete panels will be larger for protected steel columns due to their higher strength and stiffness compared to unprotected steel columns. If these connections fail, the walls could collapse outwards. To investigate the effect of the column protection on the overall behaviour of the building, analytical models with all the steel columns protected with cast in-situ concrete to either full or two-thirds of the height were also analysed. 


\section{ANALYTICAL BACKGROUND}

\subsection{Fire exposure}

The fire curve used in most of the analyses in this study was the ISO 834 Standard Fire [7]. However, while the ISO fire is intended to represent fires in small compartments it was used in this study as a means of comparison between the different cases studied. The behaviour of a fire in a large compartment, such as warehouses or industrial buildings, is not the same as a small enclosure fire. These buildings usually have very high ceilings and large open spaces. The fire plume will have entrained a large amount of cold air when it impinges on the ceiling. The hot gases will continue to spread across the ceiling and similarly, cold air will be entrained into the ceiling jet. Therefore, the radiant heat flux from the upper hot layer may not be high enough to cause flashover. There is also likely to be venting through melted skylights and partial collapse of the roof in due course. For these reasons, the Eurocode External fire [8] (Figure 6) with and without a decay phase was also used for some analyses. This facilitates a comparison with the ISO fire to investigate the effect of the cooling phase on the response of the building.

\subsection{Analysis tool}

The main purpose of the study was to investigate the different failure modes anticipated for a typical steel portal frame building under fire conditions. For this purpose, structural fire analyses were performed using SAFIR, a non-linear finite element analysis tool [9-11]. SAFIR can be used to perform one, two and three dimensional analyses under ambient and elevated temperature conditions. Truss, beam, shell and solid elements are available in conjunction with a range of material models incorporating stress-strain behaviour at elevated temperatures including that for different steels based on Eurocode $3[12,13]$. Two dimensional solid elements were used for the thermal analyses of the beam cross-sections, and also for the separate torsional analysis carried out to determine the torsional and warping properties. The temperatures determined in the thermal analyses are used in the structural analyses to determine the behaviour at elevated temperatures. Vassant et al [14] carried out fire simulations on several industrial buildings using ABAQUS, ANSYS and SAFIR and concluded that the three computer programs generally gave close results.

Each steel portal frame was discretised into 40 beam elements [6]. The nodes of the frames had seven degrees of freedom, i.e. 3 translations, 3 rotations and 1 warping. Two nodes were created at the apex of the frame, one representing the left rafter and the other the right rafter. It was assumed that full compatibility could be achieved at the apex and warping was effectively transmitted between the two nodes. Similarly, two nodes were created at the knees to represent the column and the rafter. In this case, the nodes shared the same translations and rotations but the warping between the two nodes was not transmitted. At the column bases, the warping of the cross section was restrained by the endplate.

The ends of the purlins were joined to the nodes of the rafter (i.e. via master-slave relationships between these nodes) in a way that they behave similarly to fully fixed end supports but with rotation about the vertical axis freed. In practice, the purlins will be bolted to steel cleats which are welded to the top flange of the steel rafter. Some degree of fixity will be provided by the bolts to resist twisting about the longitudinal axis and in-plane deflection of the purlin. An assumption was made in the model that the bolts were able to provide full restraint against twisting about the longitudinal axis and in-plane rotation of the purlin. In terms of the warping of the purlins, it was neither transmitted to the rafter nor to the adjacent 
purlin since a small gap usually exists between the purlins at the support due to geometrical tolerances.

\section{RESULTS}

In order to capture all possible scenarios and to draw conclusions on the effectiveness of different design options, the building was analysed several times with different combinations of (i) fixity of the column base support; (ii) the presence/absence of axial restraint at the ends of purlin; (iii) different length of column encasement in concrete; and (iv) different fire exposures. Table 1 summarises the failure times in minutes and the collapse modes of the analyses when the building with different combinations of the first three parameters is subjected to the ISO fire while Table 2 gives the failure times and collapse modes in the case of an External fire. Results for two localised fires, one in a central bay and the other in the bay adjacent to the end bay, are given in Table 3 for the case of no column protection. The simulation end times in the tables refer either to when SAFIR was unable to converge to a solution or to the end time of the simulation was reached. The inwards mode is the acceptable mode illustrated in Figure 2(a), whereas the sway mode is the unacceptable mode illustrated in Figure 2(b). In the case of the upright mode, the columns remain straight and close to vertical, while the roof collapses inwards or is supported by the catenary action of the purlins acting as suspension members between the end walls.

It can be seen from Table 2 that the lesser temperatures reached in the External fire allow the portal frame structure to last longer than when exposed to the ISO fire. In the case of the External fire, the effect of axial restraint to the purlins is to greatly improve the building's performance, with no collapse at the end of 60 minutes fire exposure. Figures 7-8 and 10-12 show the deflected shapes at the end of the analyses for the case of the ISO fire exposure, while Figures 9 and 13 show the results of the analyses for the case of the External fire exposure. The results for localised fires in a central bay and one bay in from the end bay are shown in Figures $14 \& 15$.

During the initial stages of the fires, thermal expansion of the columns and rafters causes the apexes of the portal frames to deflect upwards. In those cases where the ends of the purlins were axially restrained, the purlins buckled out-of-plane initially due to the thermal expansion being restrained by the end wall boundary condition. However, after the first minute the purlins stabilised themselves by concentrating the out-of-plane buckling in one of the central bays. Subsequent behaviour of the portal frames depended on the base fixity and the longitudinal restraint of the purlins by the end walls.

\subsection{Support Conditions at the Column Base (no fire protection to columns)}

\subsubsection{Pinned Support Conditions}

For a steel portal frame structure with pinned base connections subjected to the ISO fire, significant sidesway of the fire-affected frames will occur in the sway mode when the fireaffected roof structure (steel rafters, purlins and brace channels) begins to fail and the sway of the fire-affected frames will result in very large horizontal deflections at the top of the columns (i.e. possibly in excess of $1 \mathrm{~m}$ ). This large deflection is mainly because the columns are pinned and can rotate about the base which offers no resistance to the out-of plane movement of the columns. After such a large outward deflection, the walls will have a high probability of collapsing outward due to P-delta overturning moment. Nevertheless, a fixed connection at the base or strong connections with the adjacent fixed base and concrete- 
encased columns may be able to restrict the outward deflection of the walls and resist the overturning tendency of the wall panels. As can be seen in Figure 7, the fire-affected purlins will deform into a catenary if axially restrained, but outwards deflections can still occur in sway mode. In the case where the purlins are not axially restrained, the roof structure will collapse to the ground and the collapsing rafters will subsequently pull some of the frames inwards but some frames show the tendency of collapsing outwards (Figure 8) in sway mode. If the wall panels were explicitly modelled, the large outward deflection combined with the Pdelta effect related to the self weight of the walls would trigger an outward collapse of some parts of the building. This failure mode (i.e. sway collapse mode) is unacceptable.

In the case of the External fire, the lower fire temperature compared to the ISO fire enables the structure to last a little longer in the case of no purlin axial restraint, but the inwards collapse mode (Figure 9a) is similar to that in the ISO fire (Figure 8). For the case where there is purlin axial restraint (Figure 9b), there was no collapse after 60 minutes of fire exposure. When the portal frame structure was exposed to an External fire that decayed after 30 minutes, there was no collapse after 120 minutes, by which time the steel temperatures had returned to ambient levels.

\subsubsection{Fixed Support Conditions}

For a steel portal frame building with bases fully fixed to the foundation subjected to the ISO fire, the deformation of the fire-affected roof structure (steel rafters, purlins and brace channels) is almost vertical without much sidesway. Immediately after the fire-affected roof structure starts to fail, the fire-affected frames will collapse inwards if the adjacent purlins are not axially restrained (Figure 10), or the purlins will deform into a catenary, axially restrained by the surrounding structure in a similar manner to that shown in Figure 7, but with less horizontal movement, and the columns will remain upright. These failure modes are acceptable provided the connections between the side walls and the supporting frames do not fail.

For the inwards collapse mode (with no restraint from purlins), the initial outwards deformations of the steel columns are less than $200 \mathrm{~mm}$ at the top of the column and are solely due to the thermal expansion of the steel portal frame. When the fire-affected roof structure shows a snap-through failure mechanism and collapses to the ground (Figure 10), the columns will be pulled inwards along with the collapsing rafters. Therefore, the side walls will collapse inwards provided the connections between the walls and the supporting frame do not fail. For the upright mode of failure (with axially restrained purlins), the sagging of the fire-affected purlins into a catenary shape will push the top portions of the columns outwards to some extent (i.e. up to $520 \mathrm{~mm}$ at the top of the column). Providing the connections to the wall panels do not fail, the walls can still be attached to the supporting frames and held in outwards inclined positions in a similar manner to that shown in Figure 7 for the pin base frame. This is acceptable according to the New Zealand concrete code [15].

In the case of the External fire, the lower fire temperature enables the structure to last longer for the case of no purlin axial restraint than in the ISO fire, but the inwards collapse mode is similar to the ISO fire behaviour shown in Figure 10. In the External fire, the fixed base portal frame structure undergoes little deformation when the purlins are axially restrained, with no collapse. 


\subsubsection{Partially Fixed Support Conditions}

Most real buildings are designed and built with partially fixed portal frame bases. To represent such conditions, the building was also analysed with the column bases simulated as partially fixed. This was done by the artifice of fixing the portal frames at the foundations and giving the beam elements attached to these fixed nodes a yield strength and modulus of elasticity that were half the actual values. (It should be noted that this does not represent $50 \%$ of full fixity). In a real portal frame, a bolted connection would be weaker and more flexible than the column itself, and this arbitrary partial fixity used in these analyses was considered adequate to determine whether the fire performance was more like that for the fixed base case or that for the pin base case. A more detailed investigation of the base connection was outside the scope of this study.

The analyses show that the collapse mechanisms of a building with portal frames partially fixed at the base are similar to the structure with fully fixed support conditions. If the purlins fixed to the fire-affected steel frames are axially restrained by the end walls, the purlins will deform into a catenary as shown in Figure 11a with the protected columns remaining upright. On the other hand, without restraint from the purlins, the portal frame columns and the attached wall panels will collapse inwards (Figure 11b) when the roof structure collapses to the ground. Both of these situations are acceptable.

\subsection{Passive fire protection}

For protected columns (i.e. steel columns encased in concrete, full height or $2 / 3$ height) with either full or partial base fixity, the concrete encased part of the columns will not deform excessively and will remain relatively straight during the fire. If restraint is provided by full length purlins connected to the end walls, the purlins will deform into a catenary and the columns will remain almost upright (Figure 11a). Without restraint from the purlins, the columns will collapse inwards.

If the connections between the supporting frames and wall panels do not fail, the walls will be attached to the frames and remain standing during the fire. This is acceptable as long as the walls do not collapse outwards after the fire due to failure of the connections between the panels and the columns. However, the stability of the walls after the fire becomes an issue and the walls must resist wind loads as outwards collapse after the fire is also unacceptable. In order to ensure this, the New Zealand Concrete Structures Standard [3] requires that the connections be designed for a face load of $0.5 \mathrm{kPa}$ applied to the concrete walls during the fire.

In the case of pinned bases and no purlin restraint, some sidesway occurs, and if the rafters collapse to the ground the protected columns may collapse inwards or outwards (Figures 12a $\&$ b) even though the columns themselves remain straight.

\subsection{End wall connection}

In all those cases where the purlins are subject to axial restraint, the connection to the end wall must be capable of resisting the forces that develop in the purlins. These restraint forces, represented by the forces developed in the end bay purlins during an External fire are shown in Figure 13a. It can be seen that during the first 15 minutes of the fire large compression forces are developed as the purlins expand due to the rising temperatures. Then, as the temperatures increase further, the reduction in the modulus of elasticity of the steel and the 
resulting vertical displacements cause the axial forces to reduce and become constant when the fire temperatures stabilize at $660^{\circ} \mathrm{C}$.

Figure $13 \mathrm{~b}$ shows the purlin restraint forces in the case of an external fire that decays after 30 minutes. It can be seen that the behaviour is the same as in Figure 13a until the fire starts to decay, after which the compressive forces reduce and become tensile. These tensile forces become constant once the temperatures have reduced back to ambient, with a similar magnitude to the peak compressive force. These large tensile forces arise from the interaction between the purlins and the fixed end walls and the displaced portal frames as the fire temperatures decay and the purlins and portal frames attempt to undergo thermal contraction at the same time as they regain strength and stiffness due to the decreasing temperatures. If the structure is to survive such a fire, the purlin to portal frame connections and the purlin end connections must be designed to resist this level of force. This reinforces an emerging conclusion from many structural fire studies that the largest forces in many connections will occur during the decay phase of fire exposure [16]. In order to mobilise this benefit, the end walls must have stiff lateral support independent of the roof structure.

\subsection{Localised Fires}

Localised fires in the building only affect a small number of structural elements so that load sharing can occur between the fire-affected and unaffected structural members. If the adjacent parts of the structure remain at relatively low temperatures, these cooler parts can provide adequate restraint and stiffness to the heated area and the structure may deform in a steady manner for a long period of time. However, structural collapse will occur if load transfer cannot take place.

In the case of the one bay fire near the centre of the building, the results in Figure 14 show that the unheated parts of the structure provide adequate restraint to the heated area occurring near the centre of the building and no collapse takes place whether or not there is purlin restraint.

For the one bay fire near the end of the building, the results in Figure 15a \& b show that no collapse takes place when the structure has purlin restraints provided by the end walls However, when the purlin restraints are non-existant, the heated frame supporting the purlins in the end bay collapses because load-sharing cannot take place as shown in Figure $15 \mathrm{c} \& \mathrm{~d}$.

\subsection{Comparison with previous studies}

The authors are aware of only one study dedicated to investigating the fire performance of steel portal frame buildings. Wong et al [17] reported on the experimental testing of a scaled portal frame building comprising four $6 \mathrm{~m}$ span portal frames at $1.5 \mathrm{~m}$ centres and having a rafter pitch of $15^{\circ}$. The side and end walls were made of profiled steel sheeting. They also reported on the computer modelling of the fire tests and parametric studies on a range of portal frame buildings. In each of the three fire tests carried out, only a single rafter was heated with the major part of the columns remaining cold. In the first two tests the column bases were bolted to the foundations while in the third test the column bases were modified to act as true pin connections. The rafters deflected vertically and also buckled laterally between the eaves and the first purlin in the first two tests. In the third test, the rafter collapsed as did the purlins restraining it. Computer analyses showed generally good agreement with the fire test results. 
Wong et al [17] also carried out a number of parametric studies on a range of portal frames including one of $30 \mathrm{~m}$ span, $7 \mathrm{~m}$ column height, and $15^{\circ}$ pitch. This had similarities to the portal frames described herein (see Figure 4), but the member sizes were much heavier and the roof pitch was much steeper, and there were no tilt-up wall panels. Wong et al stated that while they assumed pinned bases for most of their analyses, they observed no sway failures. This is in contrast to the findings of the research reported herein. The reason for the difference might be explained by the heavier member sizes used by Wong et al and the fact that in their analyses only the rafter was heated rather than the complete portal frame.

\section{CONCLUSIONS}

The following conclusions can be drawn from the analyses carried out in this study, regarding fire performance of unprotected steel roofs supported on steel portal frames with precast concrete wall panels:

- Most portal frames failed in 15 to 20 minutes, with the type of collapse mode depending on the base fixity, the fire exposure and restraint from the purlins.

- Most pin based frames failed in an undesirable sidesway mode, for both the ISO fire and the External fire, with very little benefit provided by restraint from the purlins. The only exception was that no collapse occurred when frames with full purlin restraint were exposed to the External fire.

- Most fixed based frames with no column protection failed with the walls collapsing inwards, with a few remaining upright.

- Fixed based frames with protected columns remained upright during and after the fire exposure.

- Frames with partial base fixity generally behaved in a similar manner to fixed base frames, with either inwards collapse or no collapse of the walls.

- It was shown that steel purlins well connected to each other, and to the end walls of the building, reduced the roof deflections under fire exposure by providing catenary action over the full length of the building. In order to mobilise this benefit, the end walls must have stiff lateral support independent of the roof structure.

\section{DESIGN RECOMMENDATIONS}

\section{Support connections of the steel portal frames}

Portal frame base connections should be detailed and designed to provide some level of rotational restraint, in order to prevent the sidesway of frames and outwards collapse of wall panels.

\section{Passive fire protection to the column legs}

Provided that there is some rotational fixity at the column bases, fire protection to the steel columns (such as concrete encasement or light fire protection) can ensure that the columns and walls will remain standing during and after the fire. Concrete encasement has the advantage of both providing fire protection and increasing the base fixity.

\section{Connections between the wall panels and the supporting frames}

The wall panels must be well connected to each other and to the supporting frames so that the outwards collapse of the panels, due to both thermal bowing of the concrete walls or outwards 
movement of the columns, can be prevented. This is regardless of whether or not the steel columns are fire protected. The new New Zealand Concrete Structures Standard NZS 3101:2005 [3] requires at least two strong and well designed connections at the top of each wall panel to ensure that they are well attached to the supporting columns.

If multiple panels are used between the supporting frames, the panels must be well connected to each other such that they act as a complete unit. An eaves tie member is recommended to keep all the walls panels connected during a fire and its connections to the walls and supporting columns should be carefully detailed and designed to prevent outwards collapse of individual panels (such as illustrated in Figure 3).

\section{Connections between the end walls and purlins}

During the heating phase of a fire the thermal elongation of the purlins could possibly push the end walls outwards, but when the fire goes out this will be followed by a thermal contraction of the purlins which can induce large tensile forces in the purlins. The end wall to purlin connections need to be designed with this in mind.

\section{REFERENCES}

[1] Lim, LCS. Stability of precast concrete tilt panels in fire, Fire Engineering Research Report 00/8, University of Canterbury, Christchurch, New Zealand, 2000.

[2] O’Meagher, AJ, Bennetts, ID, Dayawansa, PH, and Thomas, IR and BHP Research Melbourne Laboratories. Design of single storey industrial buildings for fire resistance, Journal of Australian Institute of Steel Construction, 1992, Vol. 26, No.2, Australia.

[3] Standards New Zealand, Concrete Structures Standard, NZS 3101:2006, Wellington, New Zealand, 2006.

[4] Standards New Zealand, General structural design and design loadings for buildings, NZS 4203:1992, Wellington, New Zealand, 1992.

[5] Standards New Zealand, Steel Structures Standard, NZS 3404:1997, Wellington, New Zealand, 1997.

[6] Bong MW. "Structural fire performance of steel portal frame buildings", Master of Engineering (Fire) Thesis, University of Canterbury, Christchurch, New Zealand, 2005.

[7] ISO, "Fire resistance tests - elements of building construction", ISO 834-1975, International Organization for Standardization, 1975.

[8] EC1, "Eurocode 1: Basis of design and designs actions on structures", ENV1992: Part 2.2: Actions on Structures Exposed to Fire, European Committee for Standardization, Brussels, Belgium, 1994.

[9] Franssen, J-M, User's manual for SAFIR 2007: A computer program for analysis of structures subjected to fire, University of Liege, Belgium, 2007.

[10] Talamona, D. and Franssen, J-M. Nonlinear thin shell element for steel and concrete structures subjected to fire: theoretical development, J. Applied Fire Science, 2002-3, Vol. 11, No. 4, pp291-310.

[11] Talamona, D, Castagne, S and Franssen, J-M. Nonlinear thin shell element for steel and concrete structures subjected to fire: verification and validation, J. Applied Fire Science, 2003-4, Vol. 12, No. 1, pp65-81.

[12] EC3. Eurocode 3: Design of steel structures. ENV 1993: Part 1.2: General rules Structural fire design, European Committee for Standardization, Brussels, Belgium, 1995. [13] EC3. Eurocode 3: Design of steel structures. DRAFT prEN 1993: Part 1.2: General rules - Structural fire design, European Committee for Standardization, Brussels, Belgium, 2002. 
[14] Vassart, O, Cajot, LG, O’Connor, M, Shenkai, Y, Fraud, C, Zhao, B, De la Quintana, J, Martinez de Aragon, J, Franssen, JM and Gens, F. 3D simulation of Industrial Hall in case of fire. Benchmark between ABAQUS, ANSYS and SAFIR. Interflam 2004, Proceedings of the 10th International Conference, Vol. 2, Interscience Communications Limited., London, UK, 2004.

[15] Standards New Zealand, Concrete Structures Standard, NZS 3101:1995, Wellington, New Zealand, 1995.

[16] Buchanan, AH. Structural Design for Fire Safety. John Wiley \& Sons, UK. 2001.

[17] Wong, S.Y., Burgess, I.W., Plank, R.J and Atkinson, G.A., 'The Response of Industrial Portal Frames to Fires', Paper 72, Eurosteel 99, Prague. Also Acta Polytechnica, 39, (5), (1999), pp169-182. 
Table 1: Summary of analysis results for the ISO fire - frame only

\begin{tabular}{|c|c|c|c|c|}
\hline \multirow{2}{*}{ BASE FIXITY } & Column protection & None & $2 / 3$ height & Full height \\
\hline & Purlin restraint & \multicolumn{2}{|c|}{$\begin{array}{l}\text { Failure time in minutes } \\
\text { Collapse mode }\end{array}$} & \\
\hline \multirow{4}{*}{ PINNED } & No & 14.1 & 15.0 & 15.9 \\
\hline & & Sway & Sway & Sway \\
\hline & Yes & 19.6 & 16.7 & 17.2 \\
\hline & & Sway & Sway & Sway \\
\hline \multirow{2}{*}{$\begin{array}{l}\text { PARTIAL } \\
\text { FIXITY }\end{array}$} & No & $\begin{array}{l}15.6 \\
\text { Inwards }\end{array}$ & $\begin{array}{l}15.2^{*} \\
\text { Inwards }\end{array}$ & - \\
\hline & Yes & $\begin{array}{l}15.9 \\
\text { Upright }\end{array}$ & $\begin{array}{l}16.0^{*} \\
\text { Upright }\end{array}$ & - \\
\hline \multirow{2}{*}{ FIXED } & No & $\begin{array}{l}14.9 \\
\text { Inwards }\end{array}$ & $\begin{array}{l}14.2 \\
\text { Upright }\end{array}$ & $\begin{array}{l}14.7 \\
\text { Upright }\end{array}$ \\
\hline & Yes & $\begin{array}{l}18.5 \\
\text { Upright }\end{array}$ & $\begin{array}{l}17.1 \\
\text { Upright }\end{array}$ & $\begin{array}{l}19.6 \\
\text { Upright }\end{array}$ \\
\hline
\end{tabular}

* Note: 2/3 concrete encasement applied only to the columns on one side

Table 2: Summary of analysis results for an External fire - no column protection

\begin{tabular}{|c|c|c|c|}
\hline & Fire & External & $\begin{array}{l}\text { External } \\
\text { (with decay) }\end{array}$ \\
\hline $\begin{array}{l}\text { BASE } \\
\text { FIXITY }\end{array}$ & Purlin restraint & \multicolumn{2}{|c|}{$\begin{array}{l}\text { Failure time in minutes } \\
\text { Collapse mode }\end{array}$} \\
\hline \multirow{2}{*}{ PINNED } & No & $\begin{array}{l}18.4 \\
\text { Sway }\end{array}$ & - \\
\hline & Yes & $\begin{array}{l}60.0 \\
\text { No collapse }\end{array}$ & $\begin{array}{l}120 \\
\text { No collapse }\end{array}$ \\
\hline \multirow{2}{*}{ FIXED } & No & $\begin{array}{l}26.9 \\
\text { Inwards }\end{array}$ & - \\
\hline & $\overline{Y e s}$ & $\begin{array}{l}60.0 \\
\text { No collapse }\end{array}$ & $\begin{array}{l}120 \\
\text { No collapse }\end{array}$ \\
\hline
\end{tabular}

Table 3: Summary of analysis results for a localised ISO fire - no column protection

\begin{tabular}{llll}
\hline & Fire location & Central bay & One bay from end wall \\
BASE & & & \\
\cline { 2 - 4 } FIXITY & Purlin restraint & $\begin{array}{l}\text { Failure time in minutes } \\
\text { Collapse mode }\end{array}$ \\
\hline \multirow{2}{*}{ PINNED } & No & 60.0 & 18.5 \\
& Yes & Sway & Sway \\
\hline \multirow{2}{*}{ FIXED } & No & 60.0 & 60.0 \\
& & Sway & Sway \\
\cline { 2 - 4 } & Yes & 60.0 & 20.5 \\
& & No collapse & Inwards \\
\hline
\end{tabular}




\section{Figure captions}

Figure 1 - Typical industrial buildings in New Zealand [1]

Figure 2 Acceptable and unacceptable deformation modes: (a) inwards collapse, and (b) outwards sway collapse [2]

Figure 3 Outwards collapse of a wall panel

Figure 4 Dimensions and structural elements of the building

Figure 5 Purlins in the end bays attached to tilt-up end walls

Figure 6 Time-temperature curves used in the analysis

Figure 7 Deflected shapes before and after rapid sagging of roof of the pin base frame WITH purlin restraint $(\mathrm{Scale}=1 \mathrm{x})$. ISO fire

(a) Time $=13.9$ minutes

(b) Time $=19.6$ minutes

Figure 8 Sidesway collapse of the pin base frame WITHOUT purlin restraint (Scale $=1 \mathrm{x})$. ISO fire.

(a) Time $=14.12$ minutes

(b) Time $=14.13$ minutes

Figure 9a Inwards collapse of the pin base frame WITHOUT purlin restraint, at time $=18.4$ minutes $($ Scale $=1 \mathrm{x})$. External fire

Figure 9b Pin base frame WITH purlin restraint at time $=60$ minutes in External fire, showing some sidesway movement but no collapse.

Figure 10 Inwards collapse of the fixed base frame WITHOUT purlin restraint $($ Scale $=1 \mathrm{x})$. ISO fire

(a) Time $=14.90$ minutes

(b) Time $=14.92$ minutes

Figure 11a Final deflected shape of the partially fixed base frame WITH purlin restraint and $2 / 3$ concrete encasement to right column legs $(\mathrm{Scale}=1 \mathrm{x})$. ISO fire.

Figure 11b Final deflected shape of the partially fixed base frame WITHOUT purlin restraint. $2 / 3$ concrete encasement to right column legs $($ Scale $=1 x)$. ISO fire.

Figure 12a Final deflected shape of pin base frame WITHOUT purlin restraint. 2/3 concrete encasement to right column legs $($ Scale $=1 x)$. ISO fire.

Figure 12b Final deflected shape of pin base frame WITHOUT purlin restraint. Full concrete encasement to right column legs $($ Scale $=1 \mathrm{x})$. ISO fire. 
Figure 13a Purlin axial forces during an External fire

Figure 13b Purlin axial forces during an External fire with a decay phase

Figure 14 Localised fire in bay 2 near the centre of the building

(a) Fixed base portal frames WITH purlin restraint

(b) Pin base portal frames WITH purlin restraint

(c) Fixed base portal frames WITHOUT purlin restraint

(d) Pin base portal frames WITHOUT purlin restraint

Figure 15 Localised fire in bay 1 near the end of the building

(a) Fixed base portal frames WITH purlin restraint;

(b) Pin base portal frames WITH purlin restraint;

(c) Fixed base portal frames WITHOUT purlin restraint;

(d) Pin base portal frames WITHOUT purlin restraint. 


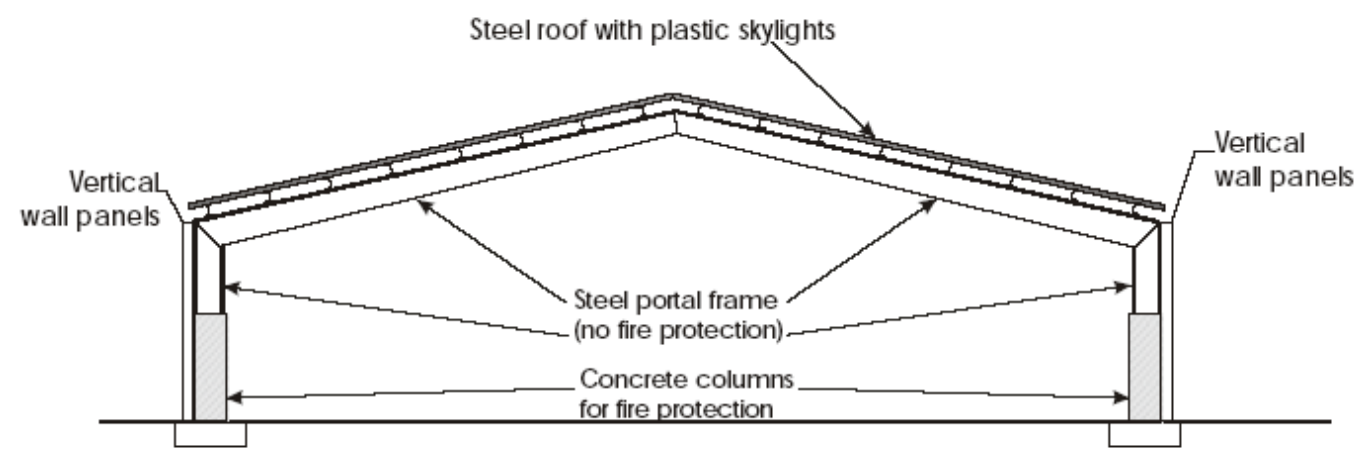

Figure 1 - Typical industrial buildings in New Zealand [1]

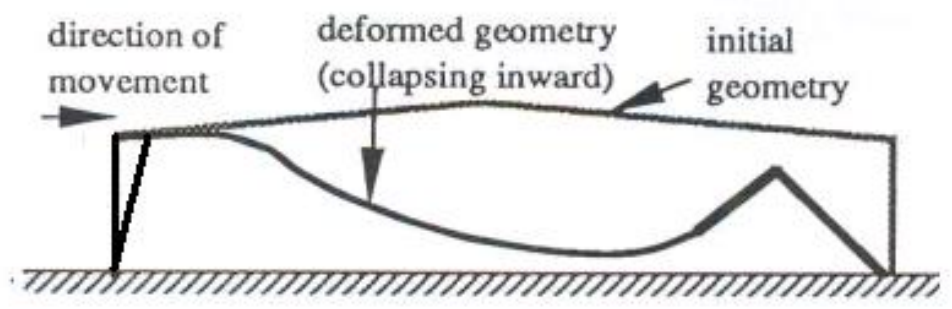

\section{a. Acceptable Deformation of Frame}

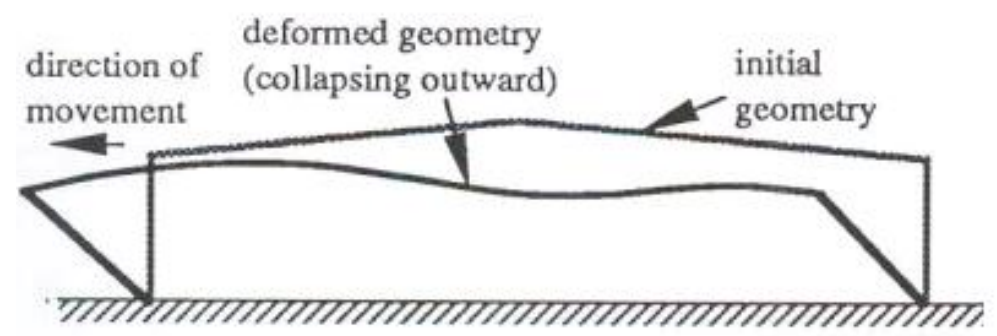

b. Unacceptable Deformation of Frame

Figure 2 Acceptable and unacceptable deformation modes: (a) inwards collapse, and (b) outwards sway collapse [2] 


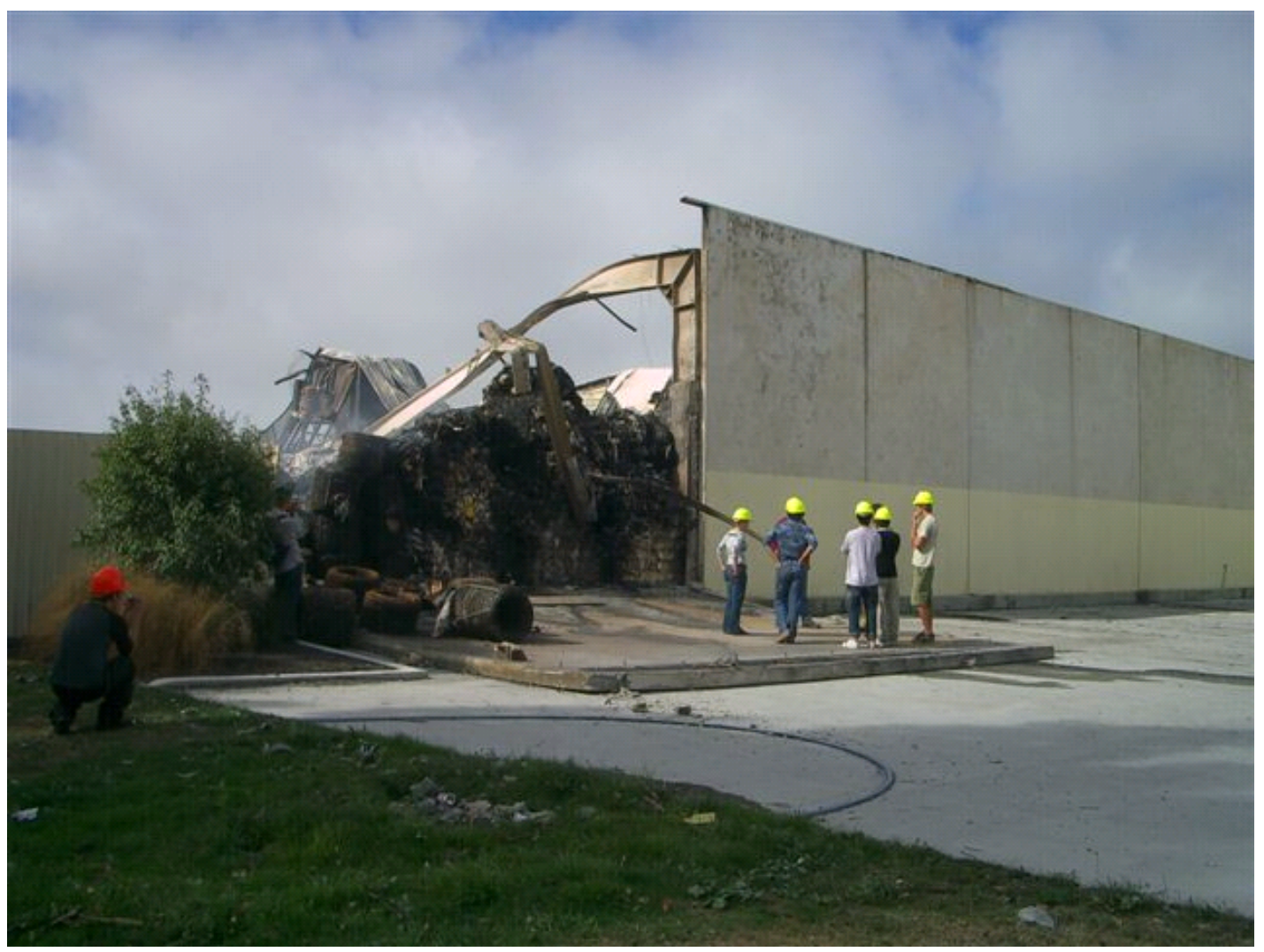

Figure 3 Outwards collapse of a wall panel

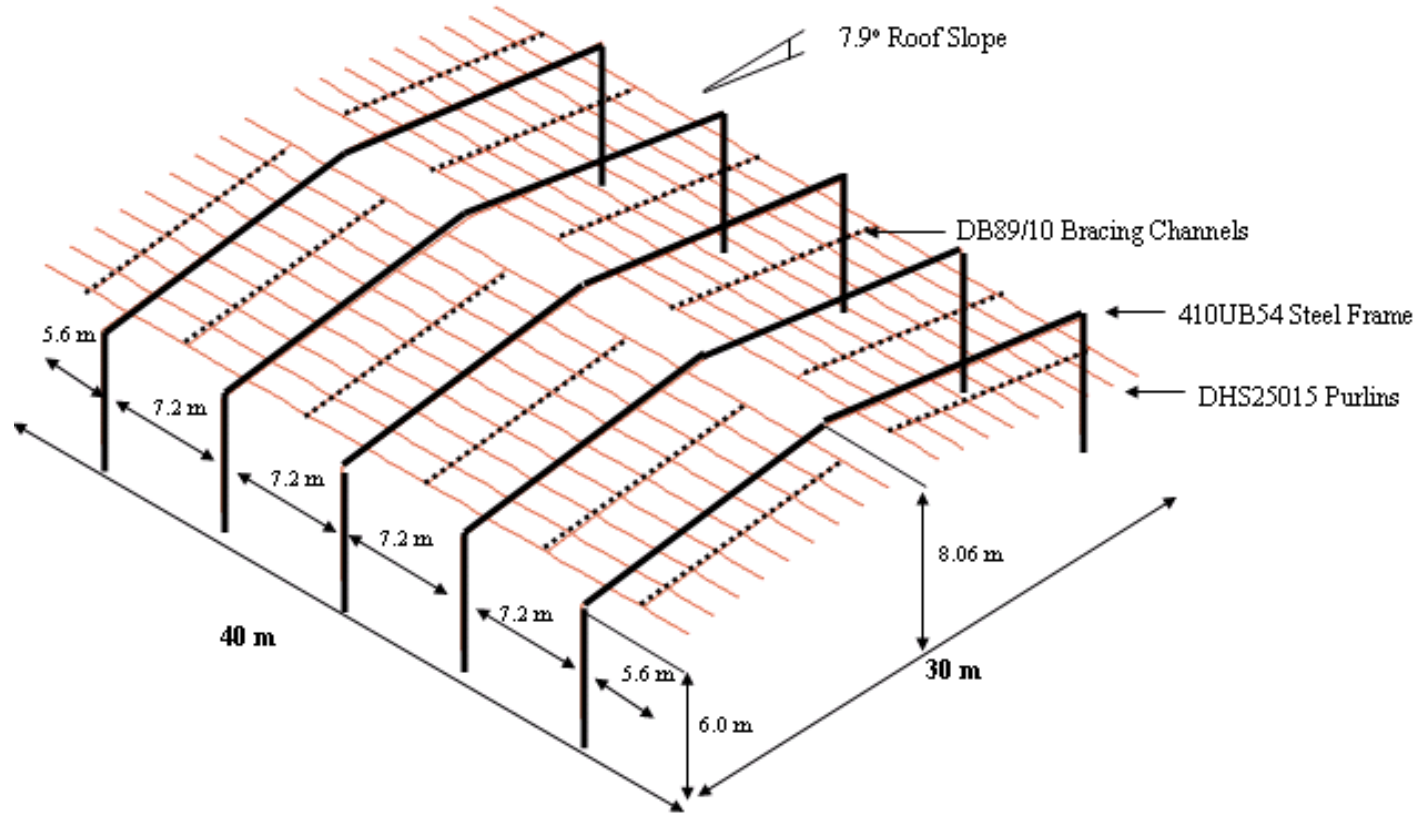

Figure 4 Dimensions and structural elements of the building 


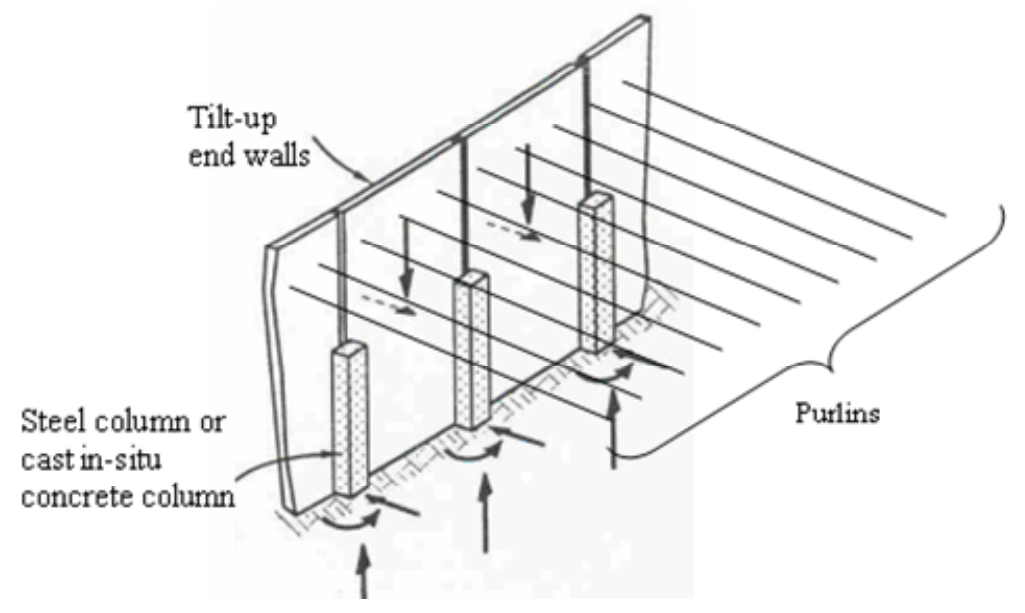

Figure 5 Purlins in the end bays attached to tilt-up end walls

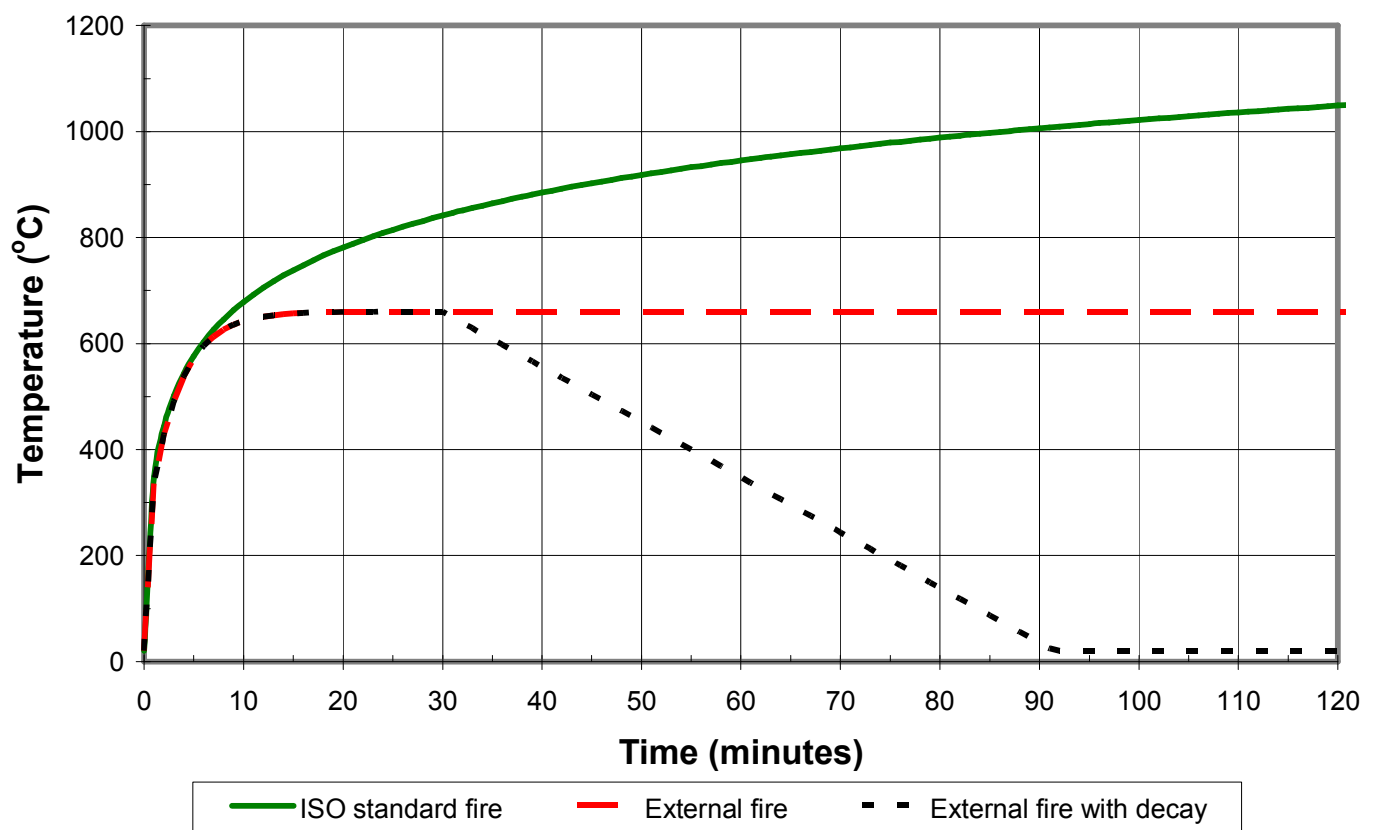

Figure 6 Time-temperature curves used in the analysis 


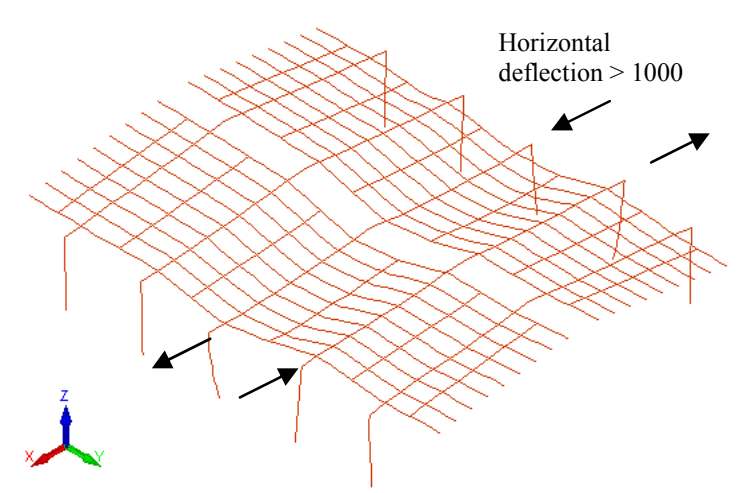

(a) Time $=13.9$ minutes

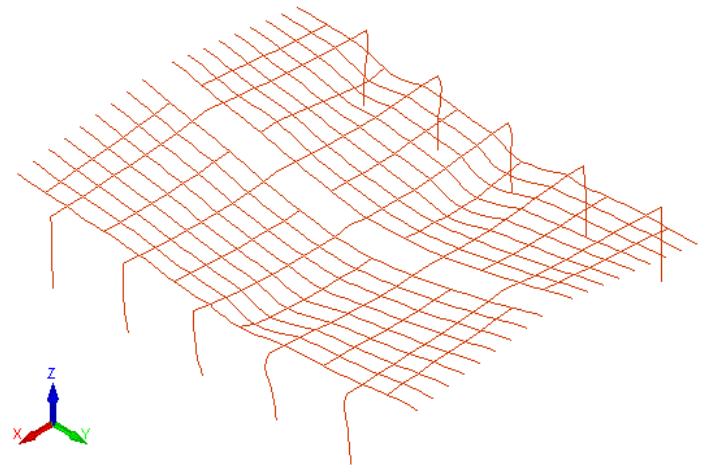

(b) Time $=19.6$ minutes

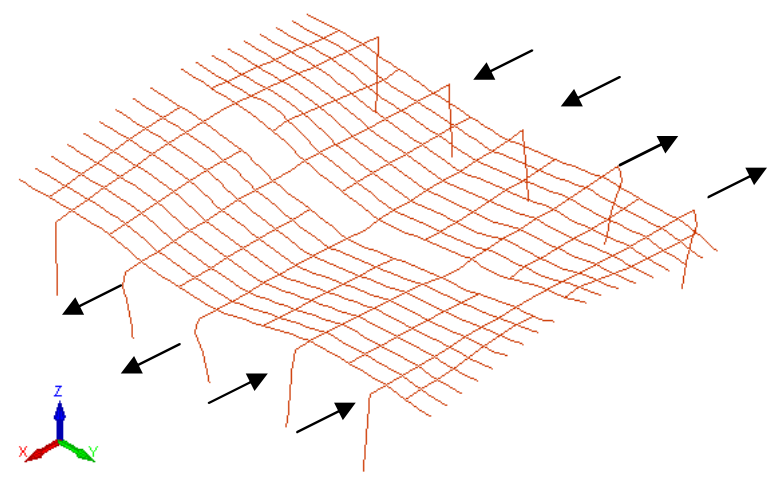

(a) Time $=14.12$ minutes

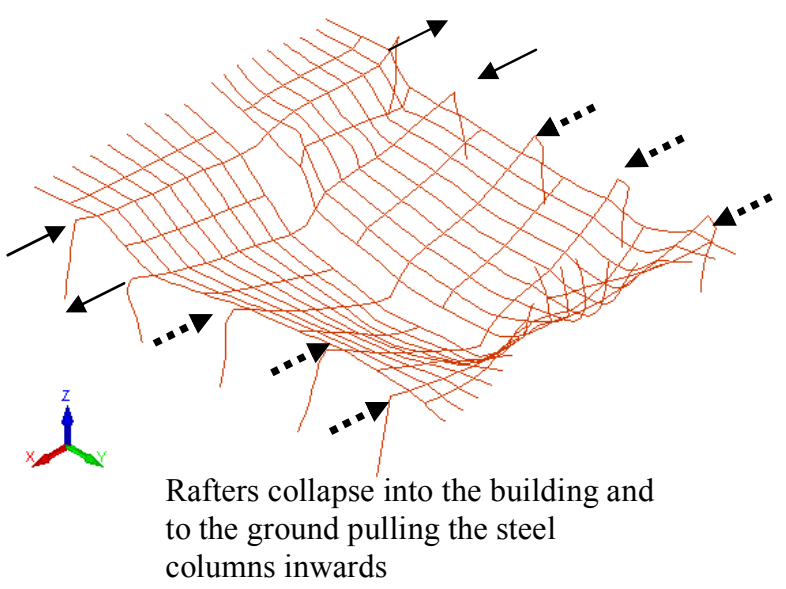

(b) Time $=14.13$ minutes

Figure 7 Deflected shapes before and after rapid Figure 8 Sidesway collapse of the pin base sagging of roof of the pin base frame WITH frame WITHOUT purlin restraint (Scale $=1 \mathrm{x}$ ). purlin restraint $(\mathrm{Scale}=1 \mathrm{x})$. ISO fire ISO fire. 


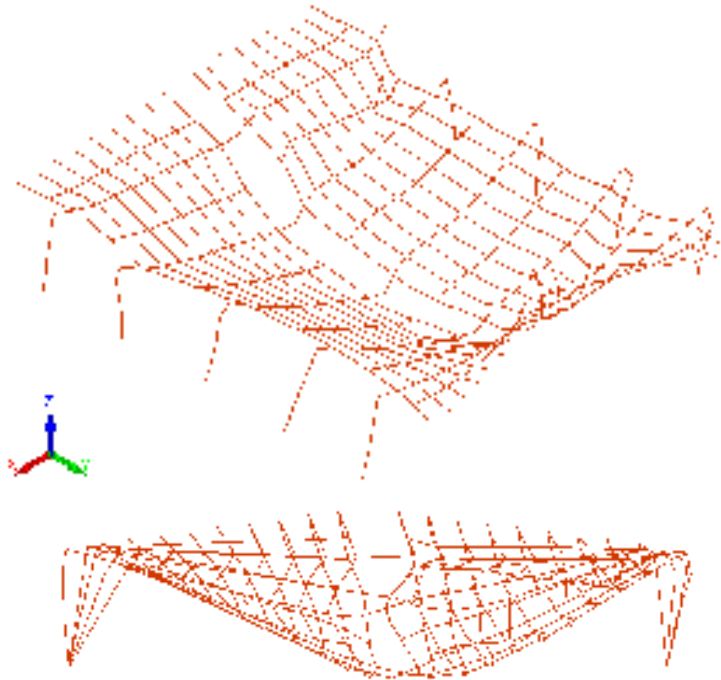

Figure 9a Sidesway and inwards collapse of the pin base frame WITHOUT purlin restraint, at time $=18.4$ minutes $($ Scale $=1 x)$. External fire.

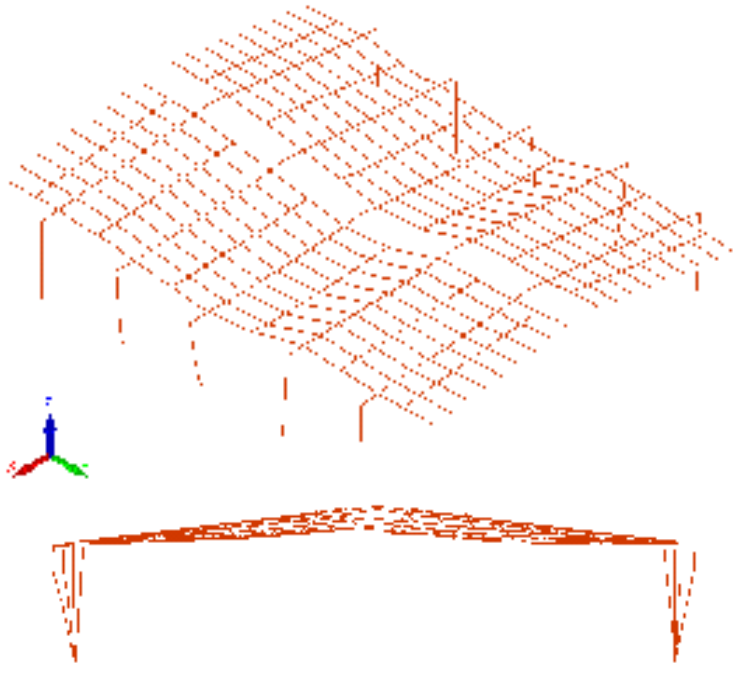

Figure 9b Pin base frame WITH purlin restraint at time $=60$ minutes in External fire, showing some sidesway movement but no collapse. 


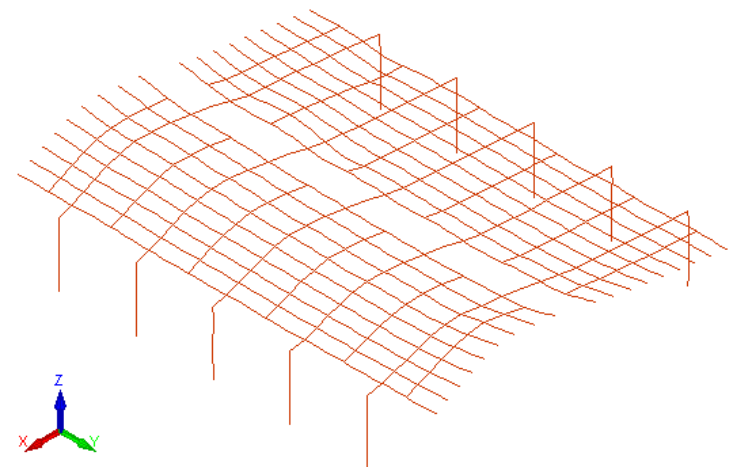

(a) Time $=14.90$ minutes

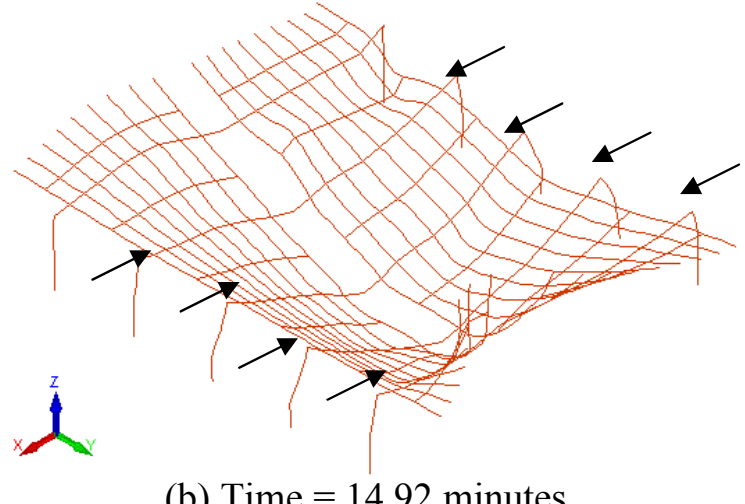

(b) Time $=14.92$ minutes

Figure 10 Inwards collapse of the fixed base frame WITHOUT purlin restraint (Scale $=1 \mathrm{x})$. ISO fire.

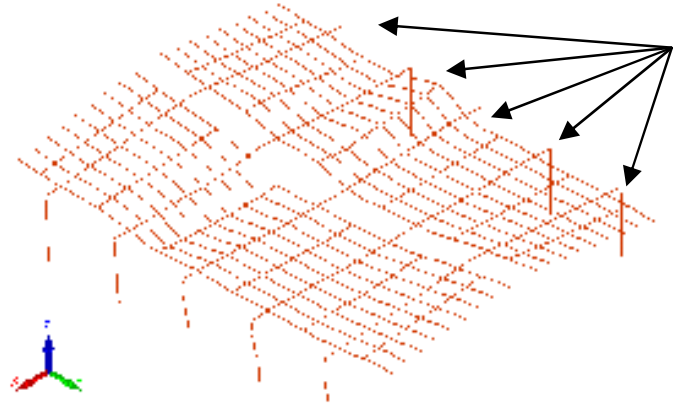

Time $=16.0$ minutes

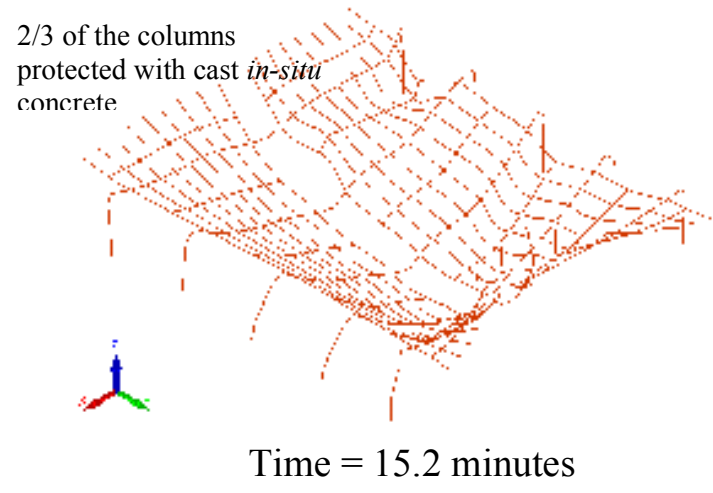

Figure $11 \mathrm{~b}$ Final deflected shape of the partially fixed base frame WITHOUT purlin restraint and $2 / 3$ concrete encasement to right column legs $($ Scale $=1 \mathrm{x})$. ISO fire. 


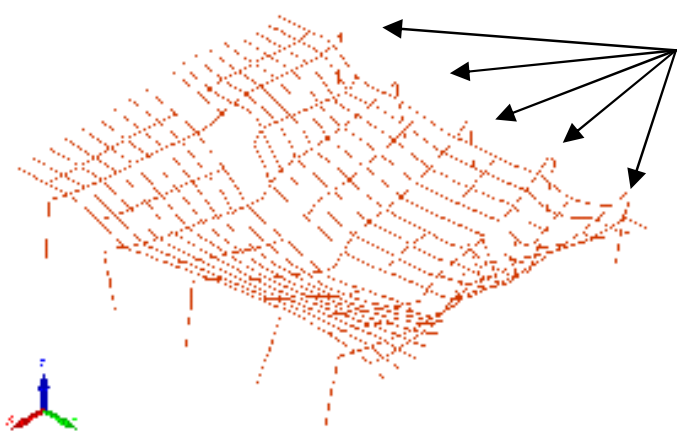

Time $=15.0$ minutes

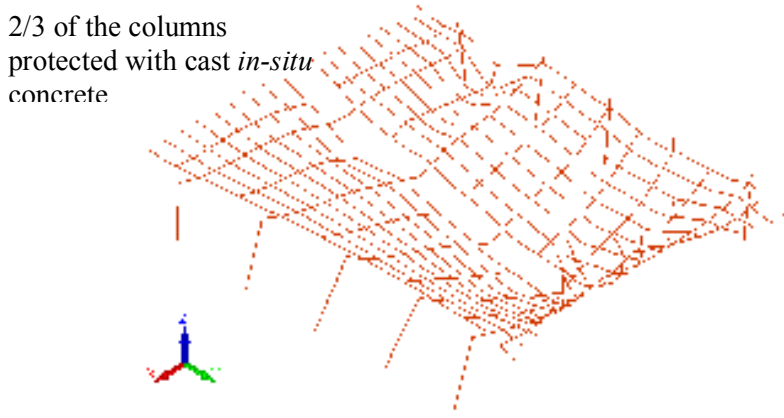

Time $=15.9$ minutes
Figure 12a Final deflected shape of pin base frame WITHOUT purlin restraint. 2/3 concrete encasement to right column legs $($ Scale $=1 \mathrm{x})$. ISO fire.
Figure 12b Final deflected shape of pin base frame WITHOUT purlin restraint. Full concrete encasement to right column legs $($ Scale $=1 \mathrm{x})$. ISO fire. 


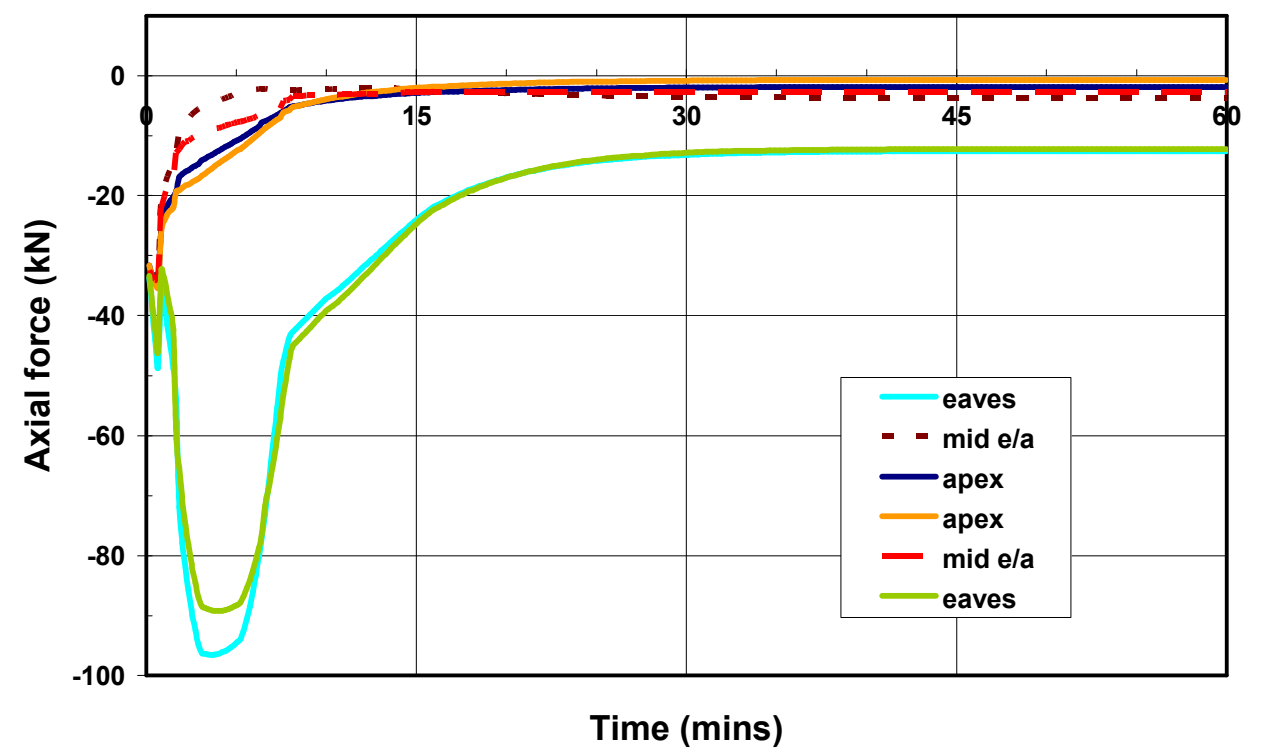

Figure 13a Purlin axial forces during an External fire

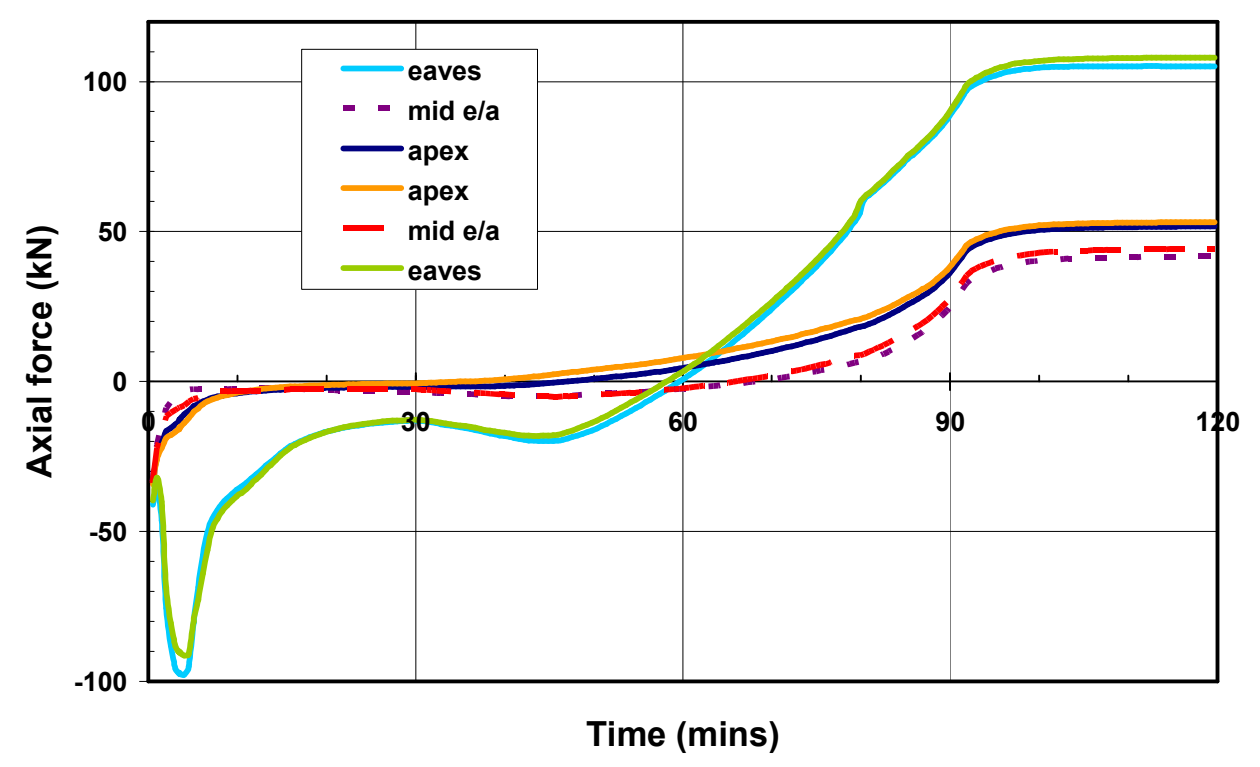

Figure 13b Purlin axial forces during an External fire with a decay phase 


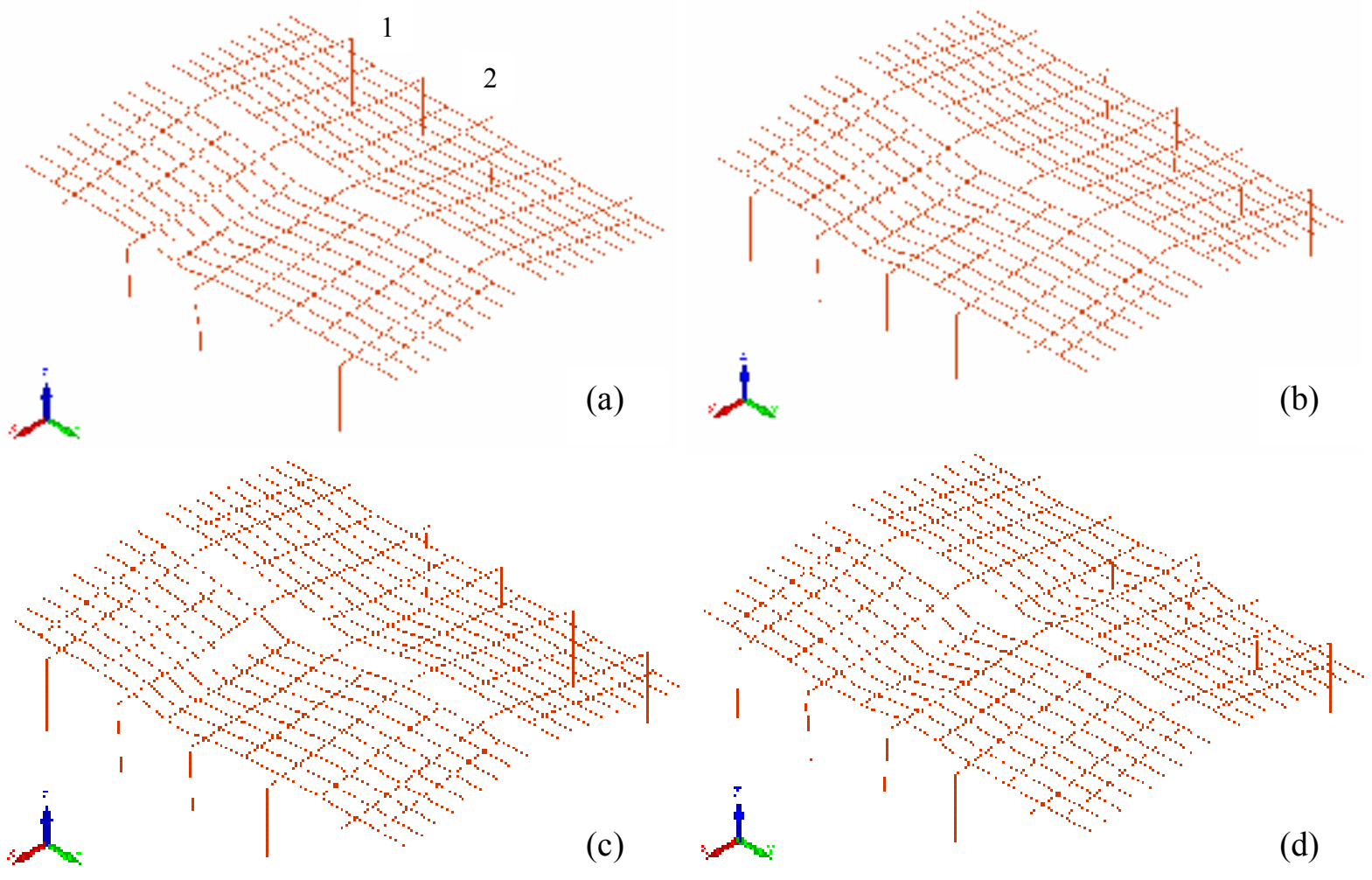

Figure 14 Localised fire in bay 2 near the centre of the building

(a) Fixed base portal frames WITH purlin restraint

(b) Pin base portal frames WITH purlin restraint

(c) Fixed base portal frames WITHOUT purlin restraint

(d) Pin base portal frames WITHOUT purlin restraint
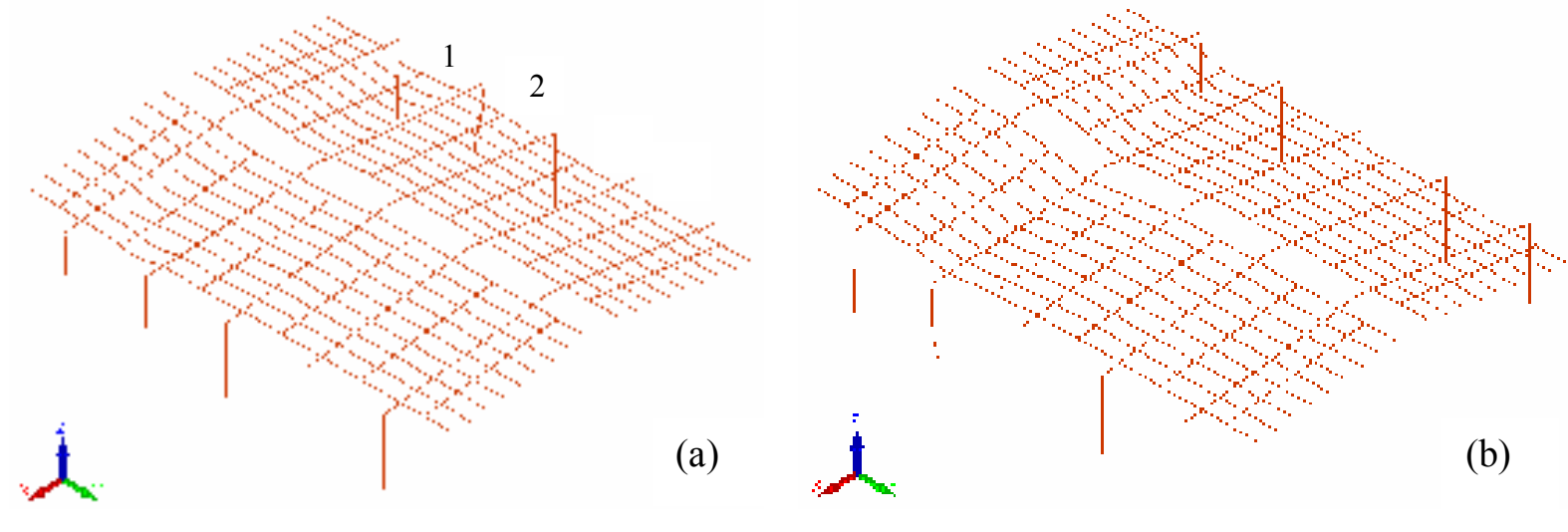


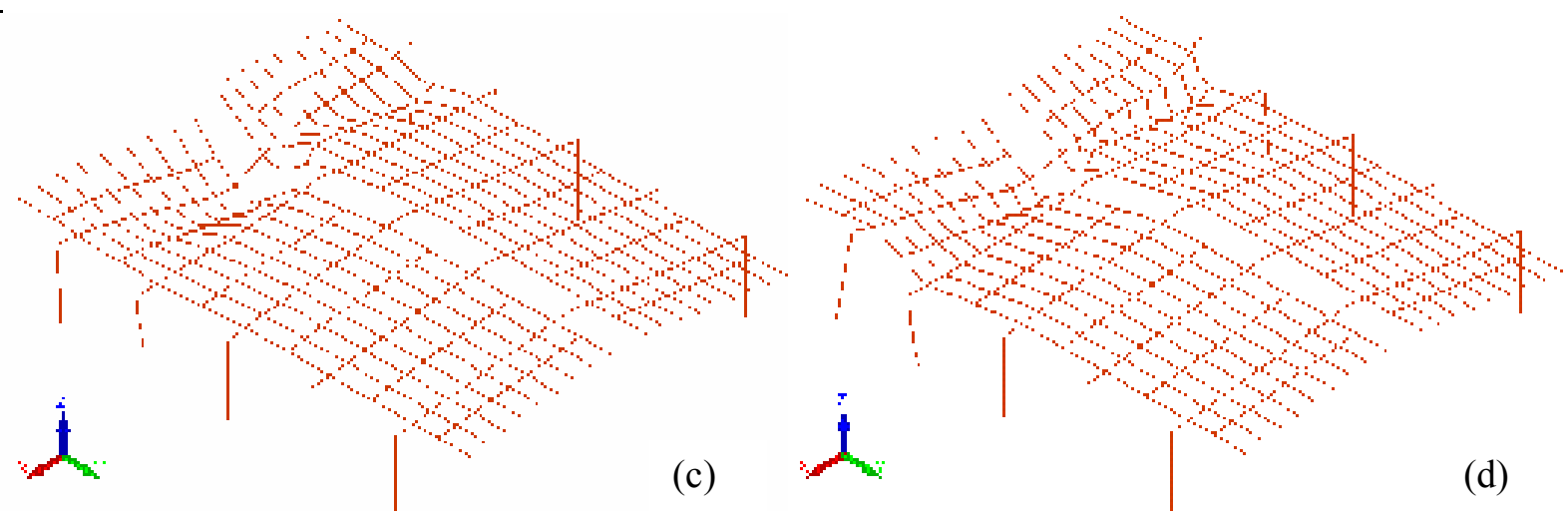

Figure 15 Localised fire in bay 1 near the end of the building

(a) Fixed base portal frames WITH purlin restraint;

(b) Pin base portal frames WITH purlin restraint;

(c) Fixed base portal frames WITHOUT purlin restraint;

(d) Pin base portal frames WITHOUT purlin restraint. 